\title{
Research Paper: The Traditional Practices of Mothers in Caring of Neonates Affected by Hyperbilirubinemia
}

\author{
Nuhad Mohammed Kassim ${ }^{1}$ (D, Ali Fadhil Obaid ${ }^{1 *}$ (D), Zainab Abdulameer Abdulrasol ${ }^{2}$ (D) \\ 1. Pediatric Health Nursing, School of Nursing, University of Babylon, Babylon, Iraq \\ 2. Maternal and Newborn Health Nursing, School of Nursing, University of Babylon.
}

\begin{tabular}{|c|c|}
\hline $\begin{array}{l}\text { Use your device to scan } \\
\text { and read the article online }\end{array}$ & Citation Mohammed Kassim N, Fadhil Obaid A, Abdulameer Abdulrasol Z. The Traditional Practices of Mothers in Caring \\
\hline 口ifirita. & $\begin{array}{l}\text { of Neonates Affected by Hyperbilirubinemia. Iranian Rehabilitation Journal. 2021; 19(4):433-440. http://dx.doi.org/10.32598/ } \\
\text { irj.19.4.1621.1 }\end{array}$ \\
\hline 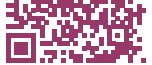 & del'http://dx.doi.org/10.32598/irj.19.4.1621.1 \\
\hline
\end{tabular}

Article info:

Received: 02 Oct 2021

Accepted: 20 Oct 2021

Available Online: 01 Dec 2021

\section{Keywords:}

Traditional practices, Neonate, Hyperbilirubinemia

\section{ABSTRACT}

Objectives: The current study aimed to identify the mothers' traditional practice in caring for newborns with jaundice; we want to determine the association between mothers' practices and their demographic characteristics.

Methods: This cross-sectional study was conducted on 100 mothers from inpatient pediatric wards of Babylon Teaching Hospital for maternal and pediatric care. They were selected by non-probability, purposive sampling method. The study data were collected by a three-part tool: demographic data sheet related to mothers and children, mothers' knowledge concerning neonatal jaundice, and the mother's knowledge and home practices concerning neonatal jaundice. The obtained data were analyzed using the SPSS version 22.

Results: Most mothers (67\%) were younger than 30 years, and 10\% had college or institute educational level. Also, $87 \%$ of mothers knew that jaundice is a common problem for neonates; $25 \%$ did not know that jaundice is abnormal if it occurs within the first 36 hours. About $17 \%$ of mothers did not agree that maternal and fetal blood group differences lead to jaundice. Besides, $47 \%$ of mothers were uncertain that severe jaundice could lead to deafness, and $78 \%$ knew that phototherapy is the treatment for jaundice.

Discussion: The majority of respondents in the study were aged 29 years or less. Most of them adopted breast and formula as the type of feeding. The most recognizable outcome of this study was the adequate knowledge and practices of mothers concerning traditional caring for neonates with jaundice.

\section{* Corresponding Author:}

Ali Fadhil Obaid

Address: Pediatric Health Nursing, School of Nursing, University of Babylon, Babylon, Iraq.

Tel: +96 (478) 10810226

E-mail:nurali.obaid@uobabylon.edu.iq 


\section{Highlights}

- Most mothers with fair knowledge and practices regarding traditional caring for neonates with jaundice.

- Majority of mothers followed mixed breast and formula as the type of feeding.

\section{Plain Language Summary}

Newborn jaundice is a prevalent condition characterized by yellowish sclera and skin of neonate because of high bilirubin levels in the blood. Complications may include seizures, or cerebral palsy, or kernicterus. The initial step in management is encouraging the mothers to continue breastfeeding to excrete the bilirubin by defecation and urination to reduce bilirubin levels in the blood as soon as possible.

\section{Introduction}

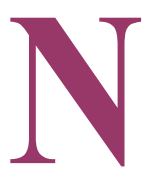

ewborn children suffer from congenital yellowing of the skin, which is the most common condition among children. Statistics indicate that $60 \%$ of full births and $80 \%$ of premature infants have yellowing of the skin $[1,2]$.

Severe hyperbilirubinemia and kernicterus are rare in developed countries where bilirubin screening, blood typing, phototherapy equipment, and Rh immunoglobulin are available. However, in developing countries where preventive, therapeutic interventions are often unavailable, severe hyperbilirubinemia causes significant morbidity and mortality [3].

Newborn hyperbilirubinemia is one of the most common reasons for hospital readmission in $60 \%$ to $80 \%$ of term newborns in the first week of life and virtually all preterm newborns $[4,5]$. It is still the foremost cause of preventable brain injury, physical and mental damage, and credible death in newborns [6].

Neonatal Jaundice (NNJ) is caused by an accumulation of unconjugated serum bilirubin, which usually replicates a normal provisional occurrence in most infants. However, when serum bilirubin levels increase disproportionately, it becomes a cause for concern. Unconjugated bilirubin is neurotoxic and can cause death in newborns or lifelong neurologic disorder, "kernicterus", including cerebral palsy and hearing loss [7]. Therefore, infants who develop jaundice require intensive care, and severe neonatal jaundice requires immediate medical consideration. That is why mothers should know enough about the risks, complications, early recognition of neonatal jaundice, and its management [8].
Kernicterus (brain damage) has at least 10\% mortality and $70 \%$ morbidity, but it can be prevented when effective therapy starts soon [9]. The neonatal mortality rate is 33 per 1000 live births (66\% of infant mortality rate), indicating the need to focus on the reduction of serious neurological complications that depend on mother knowledge and home care about NNJ [10].

Ricci et al. (2016) stated that family practices play a fundamental role in the care of newborn infants, and nursing management of newborns with hyperbilirubinemia requires a comprehensive approach [4]. The health care team includes nurses who share the responsibilities for early detection and identification, family education, management, and follow-up of the mother and newborn. Nurses can improve care by offering their support and following the "American Academy of Pediatric" guidelines in preventing hyperbilirubinemia and encouraging and maintaining successful breastfeeding. This assistance permits parents to make appropriate decisions at home [11].

Hockenbery and Wilson (2015) mentioned that Iraqi mothers practice some habits for infants, such as giving water, sugar, camel fork, and flaxseed extracts to reduce jaundice. These practices have been considered part of the culture of Iraqi mothers since ancient times. During the first days of life, newborns may have unsatisfactory breastfeeding due to numerous issues, or mothers experience pain during lactation [8]. Consequently, many families in our country believe that these remedies are active in comforting babies and curing hyperbilirubinemia. Mothers' awareness and practices in controlling infant problems play an important role in reducing symptoms of jaundice in infants [1].

The researchers did not find any study that considered Iraqi mothers' knowledge, attitudes, or behavior on the subject of NNJ. Consequently, the current study intended 
to explore the knowledge and old-style practices among Babylon mothers toward NNJ that may lead to delayed presentation and unsuitable management of severe hyperbilirubinemia.

\section{Materials and Methods}

This cross-sectional study was conducted on the mother's traditional practices in caring for children with neonatal hyperbilirubinemia. A total of 100 mothers were selected by non-probability (purposive) sampling method from inpatients of Babylon Teaching Hospital from October to November 2020.

The study questionnaire was adopted and modified for the purpose of the study. It consisted of three parts filled by interviewing mothers and completed by the researchers. All participants were informed about the study objectives, and informed consent was obtained from all mothers. The study was approved by the Scientific Committee of the Department of Child Health Nursing. The instrument consists of the following parts.

The first part was demographic data of mothers and children. This part included personal information, including the patient's age, gender, occupation, and education. The second part was related to mothers' knowledge of neonatal jaundice, and these 17 items were rated on a 3-point Likert scale (yes, uncertain, and no). The last part was related to mothers' home practices concerning neonatal jaundice. These 20 items are rated on a 3-point Likert scale (always, sometimes, and never).

The obtained data were analyzed in SPSS v. 22. We performed descriptive statistical data analysis such as frequencies and percentages, arithmetic means with standard deviation, Mean of the Score (MS) with their Mean \pm SD. For inferential statistics, we calculated the Pearson correlation.

\section{Results}

According to Table 1, 67\% of mothers were 29 years or less, and an educational level of $10 \%$ was institute or college. Regarding the gestational age, $10 \%$ of the babies had a gestational age of 35 weeks or less, and $70 \%$ of babies' birth weights were $2 \mathrm{~kg}$ or less.

According to Table 2, 87\% of mothers agreed that jaundice is a common problem for neonates. About $25 \%$ of mothers did not know that jaundice is abnormal if it occurs within the first 36 hours. Also, 17\% of mothers did not agree that jaundice is caused by maternal and fetal blood group differences. About $47 \%$ of mothers were uncertain that severe jaundice could lead to deafness, and 78\% agreed that phototherapy is the treatment for jaundice. Finally, 19\% of mothers were unsure that some maternal food intake increases jaundice than breast-fed babies.

According to Table 3, 47\% of mothers followed the traditional practice of exposing their infants to sunlight. Only $4 \%$ always checked the color of eye sclera, and $58 \%$ sometimes bathed the child well. About $11 \%$ never exposed the child to fluorescence, but $79 \%$ sometimes breastfed the child during the exposure, and finally, $16 \%$ never exposed the child to conventional home lights. The above results revealed that the mothers had adequate knowledge (67\%) of traditional caring for neonates with jaundice.

\section{Discussion}

The current study investigated a group of mothers with different sociodemographic characteristics with regard to caring for their jaundiced neonates. Based on Table 1 , $67 \%$ of mothers were 29 years old or younger, and $10 \%$ had institute or college educational degrees. These findings are inconsistent with the result of Aziz [12], who found that most mothers were older than 40 years (42\%), and a large proportion (96.7\%) of them had secondary education or above. Regarding the gestational age, a few babies have a gestational age of 35 weeks or less, and the birth weights of $70 \%$ of babies were $2 \mathrm{~kg}$ or less. These findings are supported by the research of Le et al. [3]. They found that $72 \%$ of babies had low birth weight (less than $2500 \mathrm{~g}$ ). It was also not consistent with the finding of Kotwal et al. [13]. They found that $32.9 \%$ of neonates had low weight (1500-2499 g). This result disagrees with the present results, revealing $64 \%$ of premature births (36 weeks).

Table 2 shows that $87 \%$ of mothers knew that jaundice is a common problem for neonates. Also, $25 \%$ of mothers did not agree that jaundice is abnormal if it occurs within the first 36 hours. About $17 \%$ of mothers did not know that jaundice is caused by maternal and fetal blood group differences. About $47 \%$ of mothers were uncertain that severe jaundice could lead to deafness. Also, $78 \%$ of mothers knew that phototherapy is the treatment for jaundice. Finally, 19\% of mothers were uncertain that some maternal food intake increases jaundice than breastfed babies.

The current study results indicate that most mothers were aware of the risk factors of the problem, which is consistent with Onyearugha et al.'s findings [14]. They reported that most pregnant mothers $(96 \%)$ knew jaun- 
Table 1. Demographic characteristics of mothers with newborn jaundice $(n=100)$

\begin{tabular}{|c|c|c|}
\hline \multicolumn{2}{|c|}{ Mothers' Characteristics } & \multirow{2}{*}{$\begin{array}{c}\text { No.(\%) } \\
67(67)\end{array}$} \\
\hline \multirow{3}{*}{ Age (y) } & $\leq 29$ & \\
\hline & $30-39$ & $6(6)$ \\
\hline & $>40$ & $27(27)$ \\
\hline \multirow{5}{*}{$\begin{array}{l}\text { Mothers' educational } \\
\text { level }\end{array}$} & Illiterate & $15(15)$ \\
\hline & Read and write & $33(33)$ \\
\hline & Primary & $10(10)$ \\
\hline & Intermediate and secondary & $9(9)$ \\
\hline & Institute and college & $33(33)$ \\
\hline \multirow{2}{*}{ Mothers' occupation } & Unemployed & $91(91)$ \\
\hline & Employed & 9(9) \\
\hline \multirow{2}{*}{ Residential area } & Urban & $47(47)$ \\
\hline & Rural & $53(53)$ \\
\hline \multirow{3}{*}{ Gestational age } & 35 weeks or less & $10(10)$ \\
\hline & 38 weeks or less & $63(63)$ \\
\hline & 42 weeks or less & $27(27)$ \\
\hline \multicolumn{3}{|c|}{ B: Newborns' Characteristics } \\
\hline \multirow{3}{*}{ Birth weight } & $2 \mathrm{~kg}$ or less & $70(70)$ \\
\hline & $3 \mathrm{~kg}$ or less & $28(28)$ \\
\hline & $4 \mathrm{~kg}$ or less & $2(2)$ \\
\hline \multirow{3}{*}{ Length of hospital stay } & 1-3 days & $64(64)$ \\
\hline & 4-6 days & $27(27)$ \\
\hline & 7 and more & $9(9)$ \\
\hline \multirow{4}{*}{ Feedings } & Exclusively breastfed & $34(34)$ \\
\hline & Exclusively formula-fed & $43(43)$ \\
\hline & Breast and formula & $21(21)$ \\
\hline & Breast milk and rice water & $2(2)$ \\
\hline
\end{tabular}

Iranian Rehabilitation Journal

dice risk factors. However, this finding was not supported by Olusanya et al. [15], where approximately one out of every five newborns with jaundice was associated with auditory impairment and often ABO incompatibility. According to the findings of Aziz [12] and Onyearugha et al. [16], $68 \%$ of the mothers refused to eat bananas, and $64 \%$ of pregnant mothers mistakenly thought that exposure to simple sunlight could treat children with yellowing skin. Only $4 \%$ of mothers knew about exposure to light, and $6 \%$ about using blood.

Table 3 indicates that $47 \%$ of mothers always exposed their infant to sunlight, but only $4 \%$ always checked the eye sclera color of their infants. Also, $58 \%$ of mothers sometimes bathed the child well, and $11 \%$ never exposed their infant to the fluorescent. About $79 \%$ of mothers some- times breastfeed the exposed children, and 16\% never expose their children to conventional home lights. In a particular study, most pregnant mothers (56\%) presented their babies with regular sunlight as management for jaundice.

People in sub-Saharan Africa use sunlight to treat children with yellowing skin as a popular treatment, while another study conducted by Scrafford et al. [17] revealed that $75 \%$ of mothers do not expose their children to sunlight and $93 \%$ of mothers did not wash their children. Also, $90 \%$ of them continued to breastfeed during the neonatal period. The researchers concluded that unique observed associations of jaundice with ambient air temperature and oil massage might be explained by the opportunity for phototherapy based on the cultural practices of this study population. They recommended that 
Table 2. Assessment of maternal knowledge about neonatal jaundice variables $(n=100)$

\begin{tabular}{|c|c|c|c|c|c|}
\hline \multirow{2}{*}{ No. } & \multirow{2}{*}{ Items } & \multicolumn{3}{|c|}{ No.(\%) } & \multirow{2}{*}{ Mean $\pm S D$} \\
\hline & & Yes & Uncertain & No & \\
\hline 1 & $\begin{array}{l}\text { The jaundice is yellowish discoloration of } \\
\text { newborn skin. }\end{array}$ & $91(91)$ & 9(9) & $0(0)$ & $2.91 \pm 0.288$ \\
\hline 2 & $\begin{array}{c}\text { Jaundice is a common problem for neo- } \\
\text { nates. }\end{array}$ & $87(87)$ & 9(9) & $4(4)$ & $2.83 \pm 0.473$ \\
\hline 3 & $\begin{array}{l}\text { The jaundice is abnormal if it occurs within } \\
\text { the first } 36 \text { hours. }\end{array}$ & $43(43)$ & $32(32)$ & $25(25)$ & $2.18 \pm 0.809$ \\
\hline 4 & $\begin{array}{l}\text { The jaundice is not normal if it lasts of } \\
\text { above } 2 \text { weeks. }\end{array}$ & $63(63)$ & $25(25)$ & $12(12)$ & $2.51 \pm 0.703$ \\
\hline 5 & $\begin{array}{l}\text { Breastfeeding increases the } \\
\text { rate of jaundice. }\end{array}$ & $15(15)$ & $10(10)$ & $75(75)$ & $1.40 \pm 0.739$ \\
\hline 6 & $\begin{array}{l}\text { Premature birth leads to } \\
\text { jaundice. }\end{array}$ & $43(43)$ & $40(40)$ & $17(17)$ & $2.26 \pm 0.733$ \\
\hline 7 & $\begin{array}{l}\text { Maternal and fetal blood group difference } \\
\text { lead to jaundice. }\end{array}$ & $41(41)$ & $42(42)$ & $17(17)$ & $2.24 \pm 0.726$ \\
\hline 8 & $\begin{array}{l}\text { Exposure to sunlight leads to increased } \\
\text { jaundice. }\end{array}$ & $17(17)$ & $26(26)$ & $57(57)$ & $1.60 \pm 0.765$ \\
\hline 9 & Infections increase jaundice & $46(46)$ & $38(38)$ & $16(16)$ & $2.30 \pm 0.732$ \\
\hline 10 & $\begin{array}{l}\text { Some maternal food intake increases jaun- } \\
\text { dice in breastfed babies. }\end{array}$ & 49(49) & 19(19) & $32(32)$ & $2.17 \pm 0.888$ \\
\hline 11 & $\begin{array}{l}\text { The investigation was carried } \\
\text { out when the neonate was } \\
\text { infected with jaundice }\end{array}$ & $88(88)$ & $8(8)$ & $4(4)$ & $2.84 \pm 0.465$ \\
\hline 12 & $\begin{array}{c}\text { Phototherapy is the treatment } \\
\text { for jaundice. }\end{array}$ & $78(78)$ & $18(18)$ & $4(4)$ & $2.74 \pm 0.525$ \\
\hline 13 & $\begin{array}{c}\text { Severe jaundice may lead to } \\
\text { brain damage }\end{array}$ & $88(88)$ & $7(7)$ & $5(5)$ & $2.83 \pm 0.493$ \\
\hline 14 & $\begin{array}{l}\text { Severe jaundice may lead to } \\
\text { death. }\end{array}$ & $84(84)$ & $10(10)$ & $6(6)$ & $2.78 \pm 0.543$ \\
\hline 15 & Severe jaundice can lead to deafness. & $45(45)$ & $47(47)$ & $8(8)$ & $2.37 \pm 0.630$ \\
\hline 16 & $\begin{array}{l}\text { Jaundice could be related to } \\
\text { a liver problem. }\end{array}$ & $74(74)$ & 19(19) & $7(7)$ & $2.67 \pm 0.604$ \\
\hline 17 & $\begin{array}{l}\text { Management of severe } \\
\text { jaundice is blood exchange. }\end{array}$ & $71(71)$ & $20(20)$ & 9(9) & $2.62 \pm 0.648$ \\
\hline
\end{tabular}

Iranian Rehabilitation Journa

future research should investigate the role of an infant's difficulty in feeding as a potential modifier in the association between exclusive breastfeeding and jaundice. Further study revealed that $66.5 \%$ of the mothers exposed their children to the fluorescent light. Also, $83 \%$ of the samples did not verify the color of the eyes, and $64 \%$ of pregnant mothers had the wrong belief in exposing their infants to the simple sun as a therapeutic method [14].

Concerning the overall assessment of mothers' knowledge, the current study revealed that (Figure 1) mothers had adequate knowledge (67\%) about traditional care for newborns with jaundice; this finding was supported by Pillitteri [18]. These results are consistent with Moawad et al.'s findings [9]. They reported that 52.3\% of respondents had sufficient knowledge about NNJ regarding awareness, risk factors, management, and complications. This finding indicates adequate antenatal and postnatal information on neonatal hyperbilirubinemia in the vast majority of mothers in Egypt.

Generally, frequent correct responses of knowledge related to NNJ were inconsistent across studies conducted in developing countries such as Ethiopia (63.5\%), Iran (77\%), and Turkey (46\%). This result is also inconsistent with Onyearugha et al.'s findings [14]. They found that children in Nigeria and Malaysia suffer from high yellowing of the skin due to the low level of awareness among mothers, reporting that $96.7 \%$ of mothers had a low level of knowledge. As for Egypt, the study showed that most mothers do not know about yellowing of the skin, which is helpful in diagnosis of jaundice. The adequate level of the mother's traditional practice in caring for neonatal jaundice results from high technology of Internet use, which improved their information and the close relationship between family members as a cultural habit in Iraqi society. 
Table 3. Mothers' practices to reduce the severity of neonatal jaundice $(\mathrm{N}=100)$

\begin{tabular}{|c|c|c|c|c|c|}
\hline \multirow{2}{*}{ No. } & \multirow{2}{*}{ Items } & \multicolumn{3}{|c|}{ No.(\%) } & \multirow{2}{*}{ Mean \pm SD } \\
\hline & & Always & Sometimes & Never & \\
\hline 1 & $\begin{array}{l}\text { The mother exposed her infant to } \\
\text { the sunlight. }\end{array}$ & $47(47)$ & $40(40)$ & $13(13)$ & $2.27 \pm 0.679$ \\
\hline 2 & $\begin{array}{l}\text { The mother exposed her infant } \\
\text { to the fluorescent. }\end{array}$ & $15(15)$ & $74(74)$ & $11(11)$ & $2.63 \pm 0.677$ \\
\hline 3 & Bath the child well. & $25(25)$ & $58(58)$ & $17(17)$ & $2.41 \pm 0.767$ \\
\hline 4 & Check the color of the eye sclera. & $4(4)$ & $94(94)$ & $2(2)$ & $2.92 \pm 0.339$ \\
\hline 5 & Monitor the color of urine. & $5(5)$ & $91(91)$ & $4(4)$ & $2.87 \pm 0.442$ \\
\hline 6 & Monitor the color of the stool. & $3(3)$ & $94(94)$ & $3(3)$ & $2.91 \pm 0.379$ \\
\hline 7 & Exposure child continues to breastfeeding. & $13(13)$ & 79(79) & $8(8)$ & $2.71 \pm 0.608$ \\
\hline 8 & Used mothballs at home. & $31(31)$ & $48(48)$ & $21(21)$ & $2.27 \pm 0.790$ \\
\hline 9 & $\begin{array}{l}\text { Kept newborn in dark, enclosed } \\
\text { room. }\end{array}$ & $15(15)$ & $2(2)$ & $83(83)$ & $1.19 \pm 0.443$ \\
\hline 10 & $\begin{array}{l}\text { Used traditional, herbal, or } \\
\text { over-the-counter medication } \\
\text { during the first week. }\end{array}$ & $25(25)$ & $6(6)$ & $69(69)$ & $1.37 \pm 0.597$ \\
\hline 11 & Used herbs to treat jaundice. & $18(18)$ & $9(9)$ & $73(73)$ & $1.36 \pm 0.644$ \\
\hline 12 & $\begin{array}{l}\text { Oral drinks (e.g., herbal drinks, } \\
\text { glucose) }\end{array}$ & $20(20)$ & $12(12)$ & $68(68)$ & $1.44 \pm 0.701$ \\
\hline 13 & $\begin{array}{l}\text { Exposure to home } \\
\text { conventional lights }\end{array}$ & $30(30)$ & $54(54)$ & $16(16)$ & $2.38 \pm 0.749$ \\
\hline 14 & Mother used bead yellow. & $11(11)$ & $61(61)$ & $28(28)$ & $2.33 \pm 0.888$ \\
\hline 15 & Mother put the ring. & $16(16)$ & $66(66)$ & $18(18)$ & $2.48 \pm 0.785$ \\
\hline 16 & $\begin{array}{l}\text { The mother avoids wearing the } \\
\text { yellow dress. }\end{array}$ & $6(6)$ & $61(61)$ & $33(33)$ & $2.28 \pm 0.933$ \\
\hline 17 & $\begin{array}{l}\text { Mother's use of garlic in the form } \\
\text { of a seven-lobed necklace. }\end{array}$ & $9(9)$ & $68(68)$ & $23(23)$ & $2.45 \pm 0.845$ \\
\hline 18 & $\begin{array}{l}\text { The mother used some lentils in a } \\
\text { bag to reduce the symptoms of } \\
\text { jaundice. }\end{array}$ & $8(8)$ & $17(17)$ & $75(75)$ & $1.42 \pm 0.768$ \\
\hline 19 & $\begin{array}{l}\text { The mother avoids the yellow } \\
\text { colors in the infant's room. }\end{array}$ & $16(16)$ & $50(50)$ & $34(34)$ & $2.16 \pm 0.907$ \\
\hline 20 & Prefer to use silver sugar. & $8(8)$ & $11(11)$ & $81(81)$ & $1.30 \pm 0.659$ \\
\hline
\end{tabular}

Iranian Rehabilitation \ournal

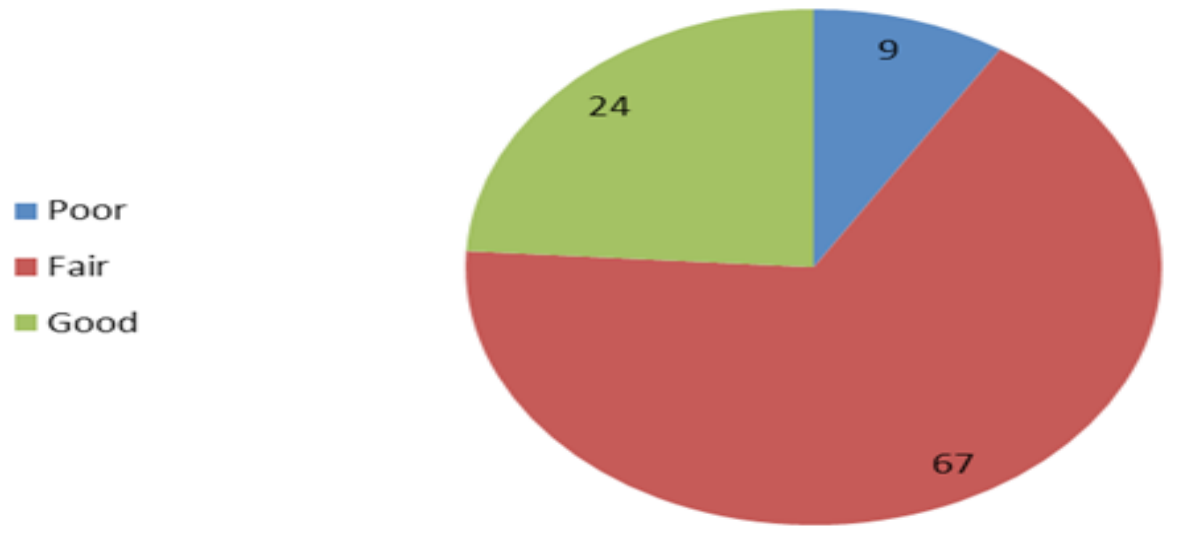

Figure 1. Overall assessment of mothers' knowledge 


\section{Conclusion}

The majority of mothers in the study were aged 29 years or less, and a lower percentage of them had an institute or college degree level of education. The majority of mothers followed breast and formula feeding. The most recognizable study outcome was the adequate knowledge and practices of mothers in traditional caring for neonates with jaundice. Mothers should be educated on modern scientific methods for caring for infants who have jaundice. This education must be provided through national programs after preparing studies to assess the cultural and scientific needs of mothers:

- The targeted and documentary programs should be offered through the public and social media about jaundice to reduce referrals to the health centers and hospitals.

- Home visits and care and health education should be provided to mothers inside the home about jaundice.

- The experience of health workers in health centers should be increased to improve their ability to diagnose jaundice and educate accordingly.

\section{Ethical Considerations}

\section{Compliance with ethical guidelines}

All ethical principles are considered in this article. The participants were informed of the purpose of the research and its implementation stages. They were also assured about the confidentiality of their information. They were free to leave the study whenever they wished, and if desired, the research results would be available to them. Written consent has been obtained from the subjects.

Funding

This research did not receive any grant from funding agencies in the public, commercial, or non-profit sectors.

Authors' contributions

All authors equally contributed to preparing this article.

\section{Conflict of interest}

The authors declared no conflict of interest.

\section{Acknowledgments}

We would like to thank the nurses in Babylon Teaching Hospital for helping me in collecting the data.

\section{References}

[1] Rabiyeepoor S, Gheibi S, Jafari S. To study the knowledge and attitude of postnatal mothers on neonatal jaundice in Motahari Hospital, Iran. Clinical Medicine Research. 2014; 3(1):1-5. [DOI:10.11648/j.cmr.20140301.11]

[2] Dharel D, Bhattarai A. Maternal perception about neonatal jaundice in eastern Nepal: A qualitative study. Health Prospect: Journal Public Health. 2017; 16(1):1-6. [DOI:10.3126/ hprospect.v16i1.17098

[3] Le LT, Partridge JC, Tran BH, Le VT, Duong TK, Nguyen HT, et al. Care practices and traditional beliefs related to neonatal jaundice in northern Vietnam: A population-based, cross-sectional descriptive study. BMC Pediatrics. 2014; 14:264. [DOI:10.1186/1471-2431-14-264] [PMID] [PMCID]

[4] Ricci SS, Kyle T. Maternity and pediatric nursing. Philadelphia: Lippincott Williams \& Wilkins; 2009. https://www. bookdepository.com/Study-Guide-for-Maternity-PediatricNursing-Susan-Ricci/9781451194012

[5] Shrestha T, Bhattarai SG, Silwal K. Knowledge and practice of postnatal mother in newborn care. Journal of Nepal Medical Association. 2013; 52(190):372-7. [DOI:10.31729/ jnma.2117]

[6] Ip S, Chung M, Kulig J, O'Brien R, Sege R, Glicken S, et al An evidence-based review of important issues concerning neonatal hyperbilirubinemia. Pediatrics. 2004; 114(1):e130-53. [DOI:10.1542/peds.114.1.e130] [PMID]

[7] Boo NY, Gan CY, Gian YW, Lim KS, Lim MW, KrishnaKumar H. Malaysian mothers' knowledge \& practices on care of neonatal jaundice. Medical Journal of Malaysia. 2011; 66(3):239-43. [PMID]

[8] Hockenberry MJ, Wilson D. Wong's nursing care of infants and children. 10th ed. London: Elsevier Health Sciences; 2015. https://books.google.com/books/about/Wong_s_Nursing_Care_of_Infants_and_Child.html?id=5c9sBQAAQBAJ

[9] Moawad EMI, Abdallah EAA, Ali YZA. Perceptions, practices, and traditional beliefs related to neonatal jaundice among Egyptian mothers: A cross-sectional descriptive study. Medicine. 2016; 95(36):e4804. [DOI:10.1097/ MD.0000000000004804] [PMID] [PMCID]

[10] Kaplan M, Slusher T, Renbaum P, Essiet DF, Pam S, Levy-Lahad E, et al. (TA)n UDP-glucuronosyltransferase 1A1 promoter polymorphism in Nigerian neonates. Pediatric Research. 2008; 63(1):109-11. [DOI:10.1203/ PDR.0b013e31815b8e7e] [PMID]

[11] Simmons B. Clinical reasoning: Concept analysis. Journal of Advanced Nursing. 2010; 66(5):1151-8. [DOI:10.1111/ j.1365-2648.2010.05262.x] [PMID]

[12] Aziz AR. Practices and believes of mothers toward treatment of newborns jaundice. kufa Journal for Nursing sciences. 2013; 3(3):54-62. https://www.iasj.net/iasj/article/82376

[13] Kotwal YS, Yatoo GH, Ahmed Jan FA. Morbidity and mortality among neonates admitted to a neonatal intensive care unit of a tertiary care teaching hospital of Jammu and Kashmir (India). Journal of Neonatal and Pediatric Medicine. 2017; 3(2):1000136. [DOI:10.4172/2572-4983.1000136]

[14] Onyearugha CN, Onyire BN, Ugboma HAA. Neonatal jaundice: Prevalence and associated factors as seen in Federal 
medical centre Abakaliki, Southeast Nigeria. Journal of clinical medicine and research. 2011; 3(3):40-5. https:/ / academicjournals.org/journal/JCMR/article-abstract/A80CFFD4366

[15] Olusanya BO, Ezeaka C V, Ajayi-Obe EK, Mukhtar-Yola M, Ofovwe GE. Paediatricians' perspectives on global health priorities for newborn care in a developing country: A national survey from Nigeria. BMC International Health and Human Rights. 2012; 12:9. [DOI:10.1186/1472-698X-12-9] [PMID] [PMCID]

[16] Onyearugha CN, Chapp-Jumbo A, George IO. Neonatal jaundice: Evaluating the knowledge and practice of expectant mothers in Aba, Nigeria. Journal of Health Science Research. 2016; 1(2):42-7. [DOI:10.18311/jhsr/2016/v1/i2/4918]

[17] Scrafford CG, Mullany LC, Katz J, Khatry SK, LeClerq SC, Darmstadt GL, et al. Incidence of and risk factors for neonatal jaundice among newborns in southern $\mathrm{N}$ epal. Tropical Medicine \& International Health. 2013; 18(11):1317-28. [DOI:10.1111/tmi.12189] [PMID] [PMCID]

[18] Pillitteri A. Maternal \& child health nursing: Care of the childbearing \& childrearing family. Philadelphia: Lippincott Williams \& Wilkins; 2010. https://books.google. com/books/about/Maternal_Child_Health_Nursing. html?id=apeLf0mPx1QC 